\title{
DUMPING: COMPARAÇÃO DE PREÇOS E TRANSFERÊNCIA DE PREÇOS NO ACORDO DA RODADA DO URUGUAI
}

\author{
Adriano da Nobrega Silva* \\ adrianodanobrega@gmail.com
}

\section{RESUMO}

Este artigo analisa a adequação do Acordo Geral de Tarifas e Comércio no que se refere ao fenômeno do dumping, da comparação de preços e dos preços de transferência, levando em conta o desenvolvimento das operações internas de empresas associadas.

Palavras-Chaves: Dumping; Comparação de preços; Preços de transferência; OMC (Organização Mundial do Comércio); Rodada do Uruguai.

\section{Dumping, comparison of prices and transfer pricing in the Uruguay Round}

\begin{abstract}
This paper analyses the General Agreement on Trade and Tariffs and its application to the phenomenon of prices comparison and transfer pricing, taking in account the development of the intra-operations of associated enterprises.
\end{abstract}

Keywords: Dumping; Prices comparison; Transfer pricing; WTO (World Trade Organization); Uruguay Round.

\footnotetext{
* Professor do UNICEUB. Consultor Legislativo da Câmara dos Deputados. Pesquisador do Grupo Integrado de Pesquisa em Direito Internacional Econômico em Sistemas de Integração.
} 


\section{Introdução}

Desde o Acordo Geral de Tarifas e Comércio (General Agreement on Trade and Tariffs - GATT) houve a manifesta preocupação com a eliminação de barreiras, tarifárias ou não, ao comércio internacional, com base na crença de que sua liberalização seria um adequado instrumento para a melhoria da qualidade de vida, garantia do pleno emprego e do crescimento da renda.

Uma vez realizada a importação de um determinado produto, com o cumprimento de todos os deveres - inclusive aduaneiros - previstos pelo país importador, ele não poderia sofrer qualquer espécie de discriminação em relação aos produtos similares nacionais, conforme o disposto no Artigo III do GATT. O principio da não-discriminação, evidentemente, tem por pressuposto a realização da importação em condições de livreconcorrência.

O GATT prevê a possibilidade da verificação do respeito à livre concorrência sempre que um produto tenha sido importado por um valor inferior ao seu preço normal, determinado em condições de livre mercado, ou seja, com discriminação de preços. Diz-se, nesse caso, que houve a prática de dumping e o exportador, em virtude desse fato, pode vir a sofrer uma sanção jurídica se tal discriminação causar, ou mesmo ameaçar causar, um dano à indústria do país importador ou retardar a sua consolidação econômica. A sanção jurídica correspondente será a imposição dos chamados direitos antidunping, observando-se as disposições do Artigo VI do Acordo.

As investigações antidumping vêm se tornando um assunto de importância cada vez maior para o comércio internacional. Se, em um primeiro momento, no âmbito do GATT, as renegociações tarifárias e as restrições voluntárias às exportações foram instrumentos altamente utilizados pelos Estados a fim de regular suas relações comerciais internacionais, mais recentemente aquelas ações são as mais utilizadas ${ }^{1}$. O Gráfico 1 abaixo mostra a evolução, em termos quantitativos, das renegociações tarifárias

\footnotetext{
1 E isso apesar da existência de estudos sobre dumping desde a década de 20, no âmbito da Sociedade das Nações. THERON, Nicola. Anti-dumping procedures: lessons for developing countries with special emphasis on the South Africa Experience. Disponível em $<$ http://www.sba.muohio.edu/abas /1998/antidumping.pdf $>$ Acesso em 9 dez 2003.
} 
(primeira coluna em ordem de aparição), das ações emergenciais (segunda coluna em ordem de aparição) e das restrições voluntárias de exportações (última coluna).

Um dos compromissos assumidos pelos países, ao se tornarem signatários do GATT, era o de diminuir as alíquotas dos impostos incidentes sobre o comércio internacional. O gráfico evidencia o fato de que, apesar desse compromisso, durante os primeiros quinze anos de existência do GATT, os 29 países signatários renegociaram, pelo menos uma vez, suas alíquotas, tendo sido realizadas no período 110 renegociações, uma média de quase quatro por país.

$\mathrm{O}$ outro instrumento bastante utilizado nesses primeiros quinze anos foi o da utilização de ações emergenciais. Assim, os países restringiam o comércio internacional e, posteriormente, negociavam medidas compensatórias. Os dois instrumentos eram utilizados de modo complementar: das quinze ações emergenciais anteriores a 1962, 9 foram solucionadas com a renegociação das tarifas aplicáveis, na forma do Art. XXVIII do GATT.

No início da década de 1960, contudo, esses dois instrumentos passaram a ser utilizados sobre produtos de categorias de menor importância e envolvendo montantes irrisórios do comércio internacional: as restrições voluntárias de exportação passaram a ser o instrumento da vez.

Isso talvez se deva pelo fato de que as renegociações tarifárias já não fossem um instrumento tão relevante, tendo em vista as reduções das alíquotas aplicáveis verificadas ao longo do tempo, ao passo que as ações emergenciais envolviam uma série de questões relativas a prova, as quais desestimulavam a sua utilização.

As principais questões relativas ao comércio internacional passaram a ser tratadas de modo particularizado. Assim, em 1962, foi negociado um Acordo Têxtil em que se previu, pela primeira vez, a possibilidade de restrições voluntárias às exportações. Esse mecanismo foi posteriormente adotado para todos os produtos de vestuário logo no início 
das negociações do Acordo de Multifibras, passando a ser também utilizado pelos países industriais para produtos-chave, tais como o aço.

\section{Gráfico 1}

Renegociações, Ações Emergenciais e Restrições Voluntárias às Exportações entre 1948 e 1993

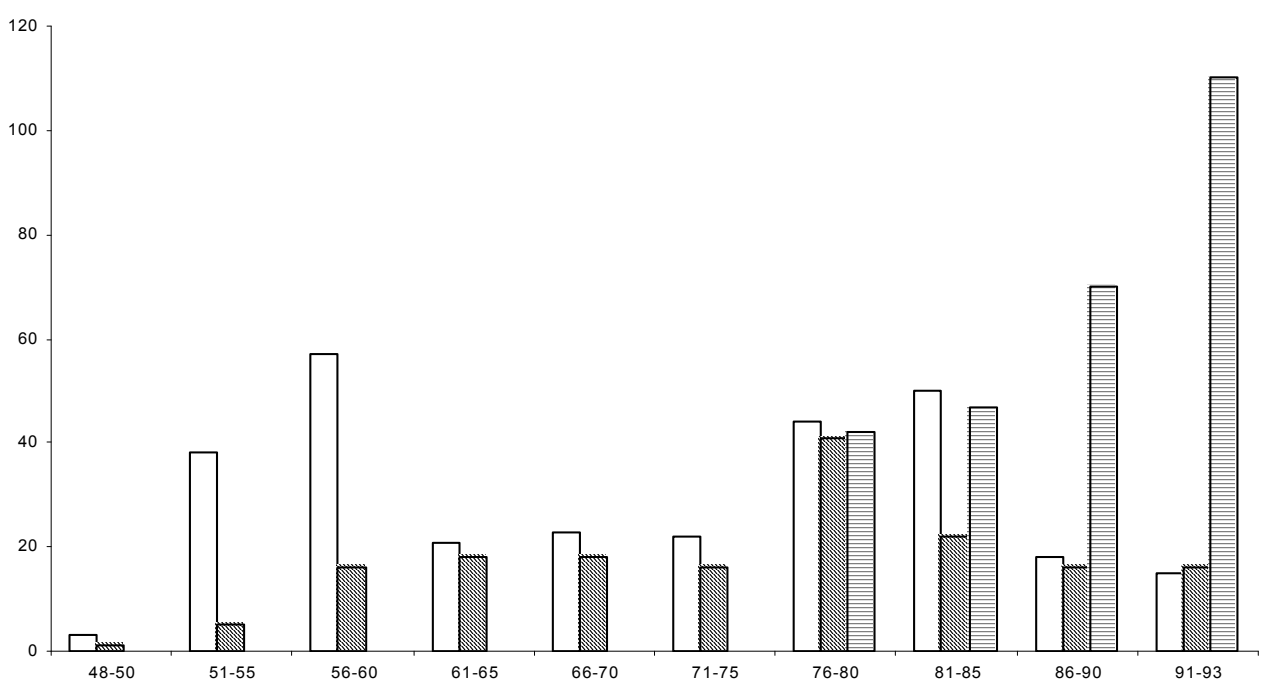

Fonte: FINGER, J. Michael. Safeguards: Making sense of GATT/WTO provisions allowing for import restrictions. In: HOEKMAN, Bernard. MATTOO, Aaditya. Development, trade, and the WTO: a handbook, 2002, p. 198

A partir da década de 80 , começou a se verificar um aumento nas chamadas ações antidumping, como demonstra o Gráfico 2.

Nos Estados Unidos, tal fato decorreu do interesse do Congresso americano em diminuir o poder discricionário do Presidente em negociar restrições voluntárias às exportações ou em implementar ações emergenciais, as quais culminavam com a restrição do acesso dos americanos aos produtos importados. Assim, foi fortalecida a legislação antidumping naquele país. 
Na Comunidade Européia, a imposição de medidas antidumping também se mostrou um instrumento adequado a regular os fluxos de entrada dos produtos asiáticos, sobretudo num momento de estagnação econômica verificado no Continente. As medidas, segundo o Tratado de Roma, somente poderiam ser aplicadas pela Comissão da União Européia e, tendo em vista as demandas dos países membros e como meio de mostrar sua própria utilidade, a comissão resolveu aplicar ações antidumping como meio de proteção das indústrias locais.

As principais razões pelas quais passou a haver uso intensivo das ações antidumping são as seguintes:

- podem ser aplicadas a exportadores individualizados;

- são ações unilaterais, não necessitando haver renegociação ou compensação;

- seus requisitos são mais facilmente demonstráveis que aqueles exigidos para as ações emergenciais;

- há o entendimento de que a prática de dumping é desleal;

- o próprio fato de se instaurar um processo de investigação tende a reduzir as importações.

Após a Rodada do Uruguai, passou a haver um uso ainda mais intensivo das medidas antidumping. Uma das razões foi a proibição da utilização das restrições voluntárias de exportações, por terem sido contrárias aos propósitos gerais da nascente Organização Mundial do Comércio. Outra razão foi a sua maior utilização pelos países em desenvolvimento, podendo-se citar o exemplo da África do Sul², que, em 1993, possuía obrigações antidumping apenas em relação a três produtos, ao passo que somente no ano de

2 THERON, Nicola. Anti-dumping procedures: lessons for developing countries with special emphasis on the South Africa Experience. Disponível em $<$ http://www.sba.muohio.edu/abas /1998/antidumping.pdf $>$ Acesso em 9 dez 2003. 
1996, iniciou trinta investigações. Para que se tenha uma idéia da magnitude da utilização das ações antidumping pelos países em desenvolvimento, basta mencionar que, entre 1995 e o primeiro semestre de 2003, a Argentina havia imposto 138 medidas, ao passo que a Comunidade Européia 184 e os Estados Unidos 196, conforme dados estatísticos da Organização Mundial do Comércio.

\section{Gráfico 2}

Renegociações, Ações Emergenciais e Restrições Voluntárias às Exportações e Ações Antidumping entre 1948 e 1993

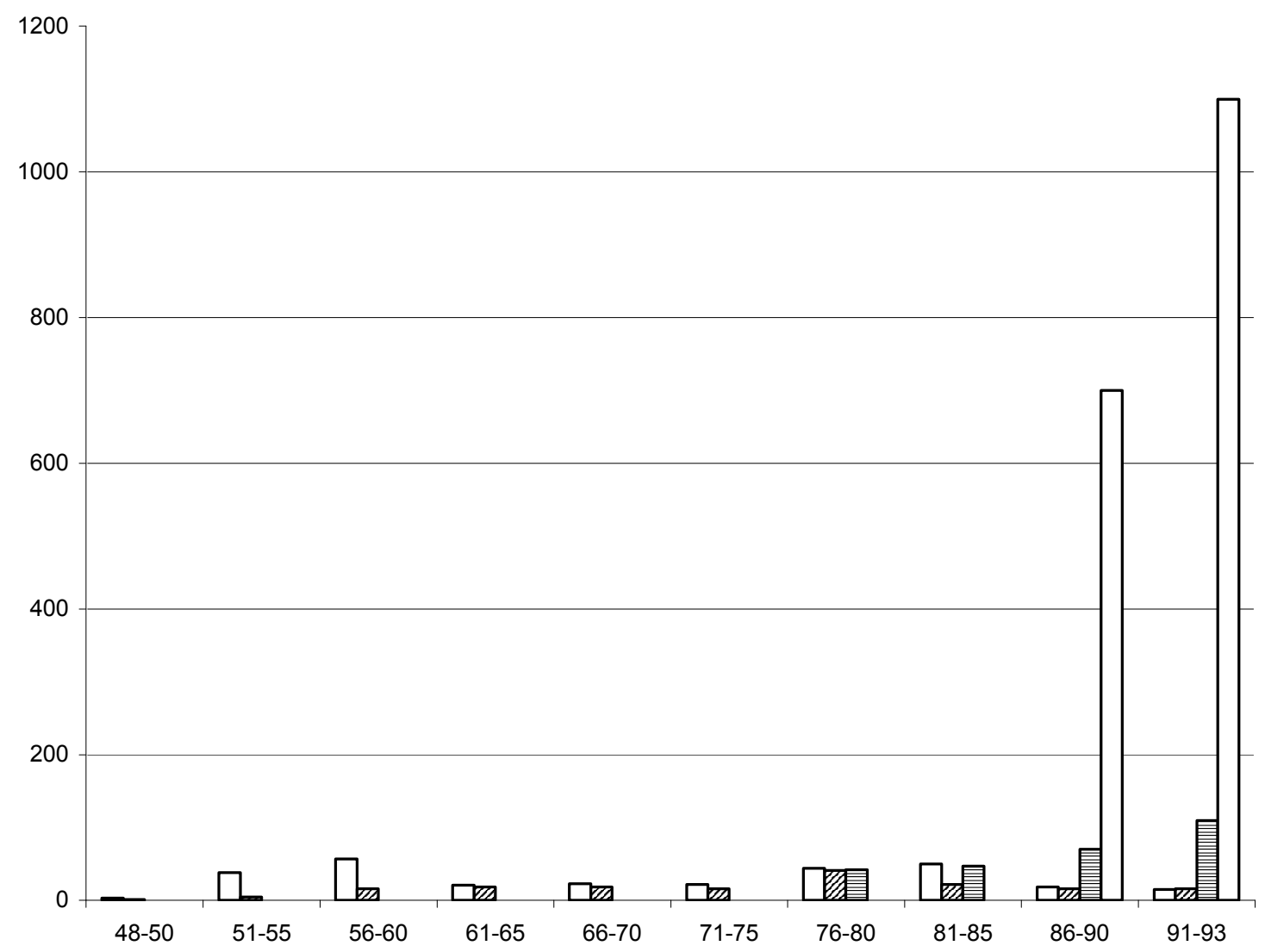

Fonte: FINGER, J. Michael. Safeguards: Making sense of GATT/WTO provisions allowing for import restrictions. In: HOEKMAN, Bernard. MATTOO, Aaditya. Development, trade, and the WTO: a handbook, 2002, p. 198 
O Gráfico 3 mostra o quantitativo das ações antidumping que foram iniciadas (primeira coluna), bem assim aquelas que foram concluídas com a imposição de deveres antidumping (segunda coluna) entre 1995 e 2001.

Nota-se que, ainda que tenha havido uma relativa estagnação no crescimento do número de investigações a partir de 2000 e da diminuição no número de medidas impostas em 2001, houve um aumento considerável no número de investigações desde 1995, passando-se de 157 para 347, bem como no de imposição de medidas, de 84, verificado em 1996, para 235 em 2000.

Gráfico 3

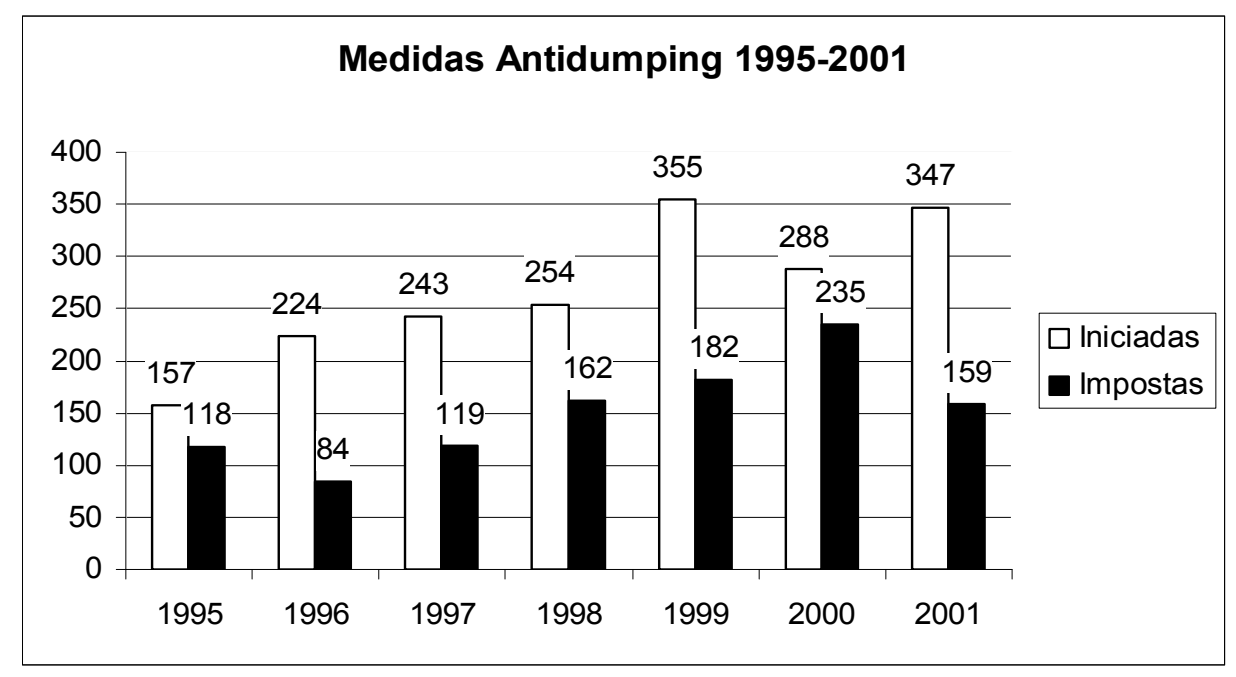

Fonte: World Trade Organization. Annual Report 2003. Genebra: WTO, 2003, p. 23.

Um aspecto que merece ser destacado, conforme o demonstrado na Figura 1, é o da elevada incidência de ações antidumping sobre produtos que, tradicionalmente, são insumos no processo produtivo, a exemplo de metais de base e derivados, os quais responderam por $38,0 \%$ do total de medidas em 2001 , bem assim produtos químicos e derivados, os quais responderam por $17,0 \%$ do total de medidas no mesmo ano. 
Esse é um ponto da maior importância ao se tratar de negociações entre pessoas associadas, tendo em vista que o produto remetido por uma das empresas do grupo a outra não será destinado diretamente a revenda, mas sim submetido a algum processo de industrialização.

O propósito do presente trabalho é analisar as disposições relativas à comparação entre o preço de exportação e o preço normal do produto, desde o Acordo do GATT até o mais recente, da Organização Mundial do Comércio (OMC), a partir dos textos legais existentes, com vistas a contextualizar a discussão, passando-se, então, a analisar casos da jurisprudência da OMC relativos a essa comparação para, em seguida, tecer algumas considerações sobre o tema, especialmente no que concerne à atuação de empresas associadas e o fenômeno da transferência de preços - assunto este que será mencionado em primeiro lugar.

Fig. 1 - Medidas antidumping em 2001 - percentuais

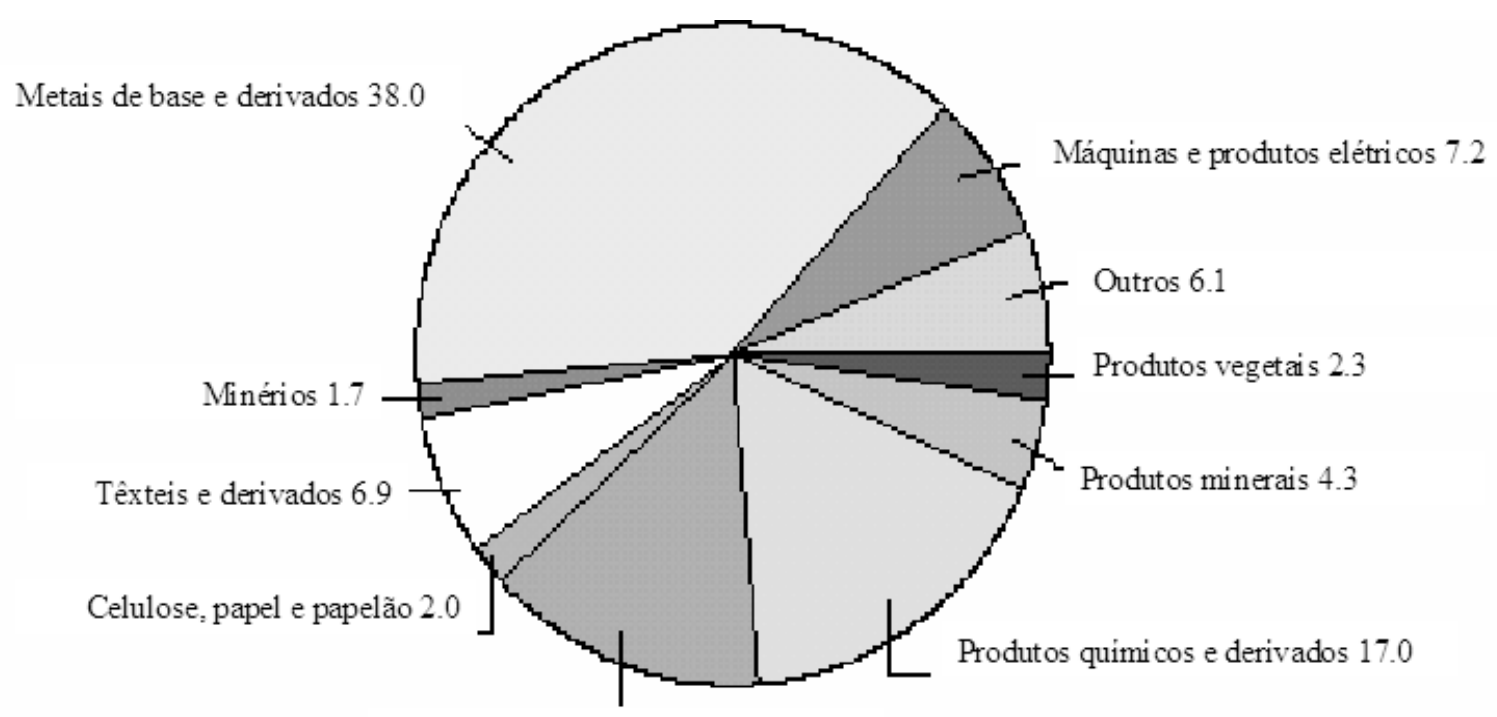

Plástico, borracha e derivados 14.4

Fonte: World Trade Organization. Annual Report 2003. WTO: Geneva, 2003. p. 24. 


\section{A transferência de preços}

A determinação do dumping está diretamente associada ao fenômeno da discriminação de preços. Baseia-se ele na clara premissa de que as forças de mercado determinam o preço adequado de um produto caso nenhum outro fator externo provoque distorção na economia. Nessa premissa, não há como se justificar que um produto seja vendido no mercado doméstico por um determinado preço, mas exportado por outro menor.

Tal entendimento vem desde as clássicas lições de Adam Smith, para quem havia uma distinção entre o preço natural do produto, qual seja, aquele suficiente para pagar os fatores produtivos - a renda da terra, os salários do trabalho e os lucros do patrimônio ou capital empregado em obter, preparar e levar a mercadoria ao mercado - e o chamado preço de mercado, ou seja, o preço efetivo ao qual uma mercadoria é vendida, o qual pode estar acima ou abaixo do preço natural, podendo também coincidir exatamente com ele, sendo regulado pela proporção entre a quantidade que é efetivamente colocada no mercado e a demanda daqueles que estão dispostos a pagar o preço natural da mercadoria ${ }^{3}$.

Ocorre que, atualmente, o comércio vem sendo realizado em escalas mundiais, sendo essa internacionalização um fenômeno inquestionável. Se antes havia compra e venda de insumos, hoje se tem mera transferência entre repartições da mesma organização. Sendo o envio de um insumo de uma filial para a sua matriz um fato econômico que deve ser refletido pelos sistemas de informações contábeis, e tendo em conta que o valor dessa operação não é mais determinado pelo preço de mercado, o valor pelo qual tal remessa é avaliada denomina-se preço de transferência ${ }^{4}$.

Ainda que se reconheça que as empresas associadas, ao negociarem entre si, procurem reproduzir a dinâmica das forças de mercado, suas relações comerciais e

3 SMITH, Adam. A Riqueza das nações: Investigação sobre sua natureza e suas causas. Introdução de Edwin Cannan, apresentação de Winston Fritsch e tradução de Luiz João Baraúna. In Os Economistas. São Paulo: Nova Cultural, 1996. v. I, pp. 109 e 110.

$4 \quad$ Por essa razão, apesar da conotação de modo de majoração de lucros e diminuição da carga fiscal sofrida pela empresa ao se tratar de preços de transferência no âmbito do direito tributário, se deve afirmar ser este um conceito neutro, indicando os preços pelos quais "se entregam bens tangíveis (acabados ou em fase intermediária de produção), se prestam serviços ou se distribuem recursos entre empresas vinculadas". SALA GALVAN, Gemma. Los Precios de transferencia internacionales: su tratamento tributario. Valencia: Tirant lo Blanch, 2003, p. 42, livre tradução do autor. 
financeiras não são afetadas pelo mercado do mesmo modo que entidades independentes. Se isso é verdadeiro ao se tratar de empresas atuando dentro de um único Estado, tal fato é ainda mais evidente ao se tratar de empresas multinacionais ${ }^{5}$. Diversos fatores, além do intuito de planejamento fiscal, podem provocar distorções nos preços de transferência, de modo a que não reflitam exatamente os preços de mercado.

Por exemplo, as empresas devem levar em conta questões governamentais (tanto provenientes de seu próprio país, quanto do país para o qual pretendem exportar seus produtos) relativas a valoração aduaneira, obrigações antidumping, bem como controles de preços ou de câmbio. Além disso, distorções nos preços de transferência podem ser causadas por exigências de ajuste de fluxo de caixa da empresa integrante de um grupo multinacional. As companhias abertas podem, ainda, sofrer pressões dos acionistas para que apresentem elevada lucratividade, sobretudo em se tratando de empresas controladoras, particularmente se suas demonstrações contábeis não forem realizadas de modo consolidado. Todos esses fatores podem afetar os preços de transferência e o montante dos lucros da empresa integrante de um grupo multinacional. ${ }^{6}$

Tendo em vista que cerca de sessenta por cento do comércio mundial é realizado por meio de empresas multinacionais, bem assim pelo fato de que as cem primeiras multinacionais detém vinte por cento dos ativos mundiais ${ }^{7}$, mostra-se relevante promover uma discussão dos métodos de comparação de preços para efeito de determinação de dumping previstos no GATT e nos acordos subseqüentes, especialmente

\footnotetext{
${ }^{5}$ Conforme a clássica expressão utilizada no âmbito da Organização para Cooperação e Desenvolvimento Econômico (OCDE).

${ }^{6}$ For example, such enterprises may be subject to conflicting governmental pressures (in the domestic as well as foreign country) relating to customs valuations, anti-dumping duties, and exchange or price controls. In addition, transfer price distortions may be caused by the cash flow requirements of enterprises within an MNE group. An MNE group that is publicly held may feel pressure from shareholders to show high profitability at the parent company level, particularly if shareholder reporting is not undertaken on a consolidated basis. All of these factors may affect transfer prices and the amount of profits accruing to associated enterprises within an MNE group. (ORGANISATION FOR ECONOMIC CO-OPERATION AND DEVELOPMENT (OECD). Transfer Pricing Guidelines for Multinational Enterprises and Tax Administrations. Paris: OECD, 1995.)

7 UNITED NATIONS. Transfer Pricing : History - State of the Art - Perspectives. Ad Hoc Group of Experts on International Cooperation in Tax Matters. Tenth meeting. Geneva, 10 - 14 September 2001. Disponível em <www.un.org> Acesso em 8 setembro 2003. SALA GALVAN, Gemma. Los Precios de transferencia internacionales: su tratamento tributario. Valencia: Tirant lo Blanch, 2003, p. 41.
} 
quando se levam em conta os aspectos relacionados com a transferência de preços entre pessoas associadas.

\section{Regulamentos sobre dumping no GATT e na OMC}

\subsection{O Artigo VI do GATT}

O GATT determina, em seu artigo VI, que seja promovida, para efeito de investigação antidumping, a comparação do preço de exportação do produto com o seu preço normal, ou seja, com o preço comparável de um produto similar destinado ao consumo no país exportador, em condições normais de comércio. Essa comparação pode ser bastante simples em alguns casos, tendo em vista que pode ser utilizado como preço normal o valor de venda do mesmo produto realizada pelo próprio exportador no mercado interno de seu país.

$\mathrm{Na}$ ausência de preços no mercado interno, o GATT estabelece que seja utilizado como preço normal o maior preço comparável de produto similar exportado para terceiro país, em condições normais de comércio, ou, alternativamente, o custo de produção no país de origem acrescido de uma margem razoável para cobrir as despesas de vendas e os lucros do exportador.

Nota-se que o GATT prevê, mesmo no caso de cotejo entre o preço de exportação e o preço normal no mercado interno, que os preços sejam comparáveis, razão pela qual, em uma cláusula geral, o Acordo determinou que poderiam ser promovidos ajustes no preço normal em função das condições da venda efetuada, dos tributos incidentes sobre a operação, bem assim por outras razões que possam afetar a comparabilidade.

No caso de a operação de importação ser realizada por uma pessoa vinculada ao exportador, passou-se a prever que a margem será calculada tendo em conta o valor pelo qual o produto for revendido pelo importador ${ }^{8}$.

\footnotetext{
Parágrafo $1^{\text {o }}$ do Artigo VI do GATT acrescentado pelo Anexo I.
} 


\subsection{O Código Antidumping da Rodada Kennedy}

Em 1963, as discussões no âmbito do GATT passaram a abordar a questão das barreiras não-tarifárias com maior intensidade. Nesse sentido, houve o reconhecimento expresso de que as práticas antidumping poderiam implicar em barreiras protecionistas contra o comércio mundial, razão pela qual foi realizado o Acordo para a Implementação do Artigo VI do Acordo Geral sobre Tarifas e Comércio, o qual ficou conhecido como Código Antidumping da Rodada Kennedy.

Os objetivos do Código eram estabelecer um procedimento público e equânime para as investigações de casos de dumping e a elaboração de regras com maior grau de determinação e uniformidade.

O Código previa a prática de dumping sempre que fosse introduzido no comércio de outro país a um preço menor que seu valor normal, qual seja, o preço comparável pelo qual um produto similar é destinado a consumo no mercado do país exportador no curso normal dos negócios.

Pela primeira vez houve a definição do que seria produto similar: o produto idêntico, em todos os aspectos, ao produto exportado, ou, na inexistência de um idêntico, de outro com características bastante semelhantes às daquele produto.

Outra inovação foi a de que, quando o produto não fosse importado diretamente de seu país de origem, seria utilizado o preço comparável de sua comercialização no mercado exportador e, apenas excepcionalmente, o preço no mercado do país de origem, exemplificando com os casos de mero reenvio através do país exportador, de inexistência de produção ou de preço comparável no país exportador.

Esse dispositivo foi redigido de forma extremamente aberta, não deixando claro em que situações seria utilizado o preço do produto no país de origem e, ao contrário, quando se utilizaria o preço no país exportador. Tal ambigüidade é altamente prejudicial para o país exportador. 
Dispôs ainda o Código que, na inexistência de vendas do produto similar no curso normal das ações de comércio no mercado doméstico do país exportador, ou quando, em razão de condições específicas do mercado doméstico do país exportador, tais vendas não permitissem comparação adequada, a margem de dumping seria determinada por meio de comparação com o preço do produto similar ao ser exportado para qualquer terceiro país, podendo ser utilizado como parâmetro o maior preço encontrado, desde que tal preço fosse representativo.

A comparação, nessa hipótese, também poderia ser feita com o custo de produção no país de origem acrescido de razoável montante por conta de custos administrativos, comercialização e outros, além do lucro, sendo que, em regra, tal margem de lucro não poderia exceder aquela normalmente verificada nas vendas de produto da mesma categoria geral no mercado doméstico do país de origem.

Nos casos em que não houvesse preço de exportação ou naqueles casos em que parecesse às autoridades envolvidas que o preço praticado não é o de mercado em virtude de associação ou arranjo compensatório entre o exportador e o importador ou um terceiro, o preço de exportação poderia ser construído com base no preço pelo qual o produto importado fosse revendido a um comprador independente, ou, na inexistência de tal revenda ou de venda nas mesmas condições em que importado, outro valor considerado razoável determinado pelas autoridades envolvidas.

A fim de que fosse realizada uma comparação justa, o Código previa que os dois preços seriam tomados no mesmo nível de comércio - normalmente no ex fabrica e considerando vendas realizadas tão simultaneamente quanto possível. Razoável tolerância seria concedida caso a caso, de acordo com sua especificidade, em razão de diferenças que afetassem a comparação de preços, entre elas diferenças nas condições e nos termos de venda, tributação e outras assemelhadas.

Ademais, estabelecia que, nos casos em que não houvesse preço de exportação ou em que parecesse às autoridades envolvidas que o preço praticado não é o de mercado em virtude de associação ou arranjo compensatório entre o exportador e o 
importador ou um terceiro, deverão ser tolerados ajustes em função de custos, entre eles tarifas e taxas, que incidam entre a importação e a revenda, e também em função dos lucros auferidos.

As disposições relativas à determinação de dumping previstas no Código da Rodada Kennedy foram praticamente repetidas no novo Código implementado na Rodada de Tóquio podendo-se afirmar que, nesse tocante, não houve nenhuma alteração no tocante à determinação de dumping a partir dos preços de exportação e normal.

\subsection{O Código Antidumping da Rodada do Uruguai}

Em 1994 foi editado novo Acordo sobre a implementação do Artigo VI do Acordo Geral sobre Tarifas e Comércio ${ }^{9}$. Uma das inovações introduzidas pelo Acordo pelo qual se constituiu a Organização Mundial do Comércio (OMC), em relação ao GATT, é que este Acordo previa que os países somente estariam obrigados aos acordos que escolhessem (o que se denominou de GATT a la carte), o que não mais é possível quando um país se torna signatário da OMC. Além disso, ao contrário do GATT, uma decisão no âmbito da OMC só deixa de ser aplicada se houver unanimidade pela sua recusa, ao passo que no Acordo anterior, se exigia o consenso para a implementação da medida deliberada, o que impedia a aplicação de muitas das decisões simplesmente porque o próprio país envolvido votava em sentido contrário.

\subsubsection{Definição de dumping}

Do mesmo modo que os acordos anteriores, o Acordo Antidumping da Rodada do Uruguai prevê, em seu Artigo 2.1, que um produto é objeto de dumping quando introduzido no mercado de outro país a um preço inferior ao seu valor normal, o que se verifica quando o preço de exportação do produto exportado de um país para outro for inferior ao preço comparável do produto similar destinado ao consumo no país de exportação, no decurso de operações comerciais normais.

\footnotetext{
9 É possível a obtenção na Internet dos textos legais da OMC em inglês em $<$ http://www.wto.org/english/docs_e/legal_e/legal_e.htm>. O mesmo site possui versão em espanhol em $<\mathrm{http}: / /$ www.wto.org/spanish/docs_s/legal_s/legal_s.htm>, bem como versão em francês em

$<$ http://www.wto.org/french/docs_ff/legal_ff/legal_f.htm $>$. Encontra-se, ainda, disponível versão dos textos em português elaborada pela Faculdade de Direito da Universidade de Coimbra em $<$ http://www.fd.uc.pt/CI/CEE/OI/OMC.GATT/OMC-Indice.htm>.
} 
Conforme o art. 2.6 do Acordo, o conceito de produto similar é o mesmo adotado desde o Acordo da Rodada Kennedy, qual seja, um produto idêntico, isto é, semelhante em todos os aspectos ao produto considerado ou, na ausência de tal produto, um outro produto que, embora não seja semelhante em todos os aspectos, apresente características muito idênticas às do produto considerado..

\subsubsection{Comparação com o preço de exportação para terceiro país}

$\mathrm{Na}$ mesma esteira que os acordos anteriores, o Acordo prevê no Artigo 2.2 a possibilidade de comparação com o preço de produto ao ser exportador para um terceiro país, não mais estabelecendo que pode ser utilizado o maior preço encontrado, tendo em conta que, nesses casos, haveria forçosamente a majoração da margem de dumping. Para tanto, é necessário que não haja vendas do produto similar no mercado interno do país exportador no decurso de operações comerciais normais ou quando tais vendas não permitirem uma comparação adequada em virtude de:

- situação especial do mercado, hipótese esta já prevista no Acordo da Rodada Kennedy; ou

- baixo volume das vendas no mercado interno do país de exportação, assim consideradas as vendas do produto similar destinado ao consumo no mercado interno do país de exportação para a determinação do valor normal caso representem $5 \%$ ou mais das vendas do produto considerado ao Membro importador, sendo, no entanto, aceitável uma percentagem inferior sempre que existam elementos de prova de que esta representa um volume de vendas internas suficiente para permitir uma comparação válida.

\subsubsection{Construção do preço a partir dos custos}

Ao invés do preço de exportação para terceiro país, admite o Acordo, nas mesmas hipóteses, a utilização de um preço, para efeito de comparação, construído a partir dos custos do exportador.

O Acordo inova ao prever a possibilidade expressa de desconsideração das vendas utilizadas para efeito de comparação quando se considere que não foram 
efetuadas no decurso de operações normais, o que se verifica sempre que realizadas a preços inferiores aos custos unitários de produção (fixos e variáveis), acrescidos dos encargos de venda, despesas administrativas e outros encargos gerais, durante um período prolongado, normalmente de um ano, mas nunca inferior a seis meses, em quantidades significativas e a preços que não permitam cobrir todos os custos dentro de um prazo razoável.

As vendas a preços inferiores aos custos unitários são consideradas efetuadas em quantidades significativas quando as autoridades estabelecerem que o preço de venda médio ponderado das transações tomadas em conta na determinação do valor normal é inferior aos custos unitários médios ponderados ou que o volume das vendas a preços inferiores aos custos unitários representa no mínimo $20 \%$ do volume vendido nas transações tomadas em consideração na determinação do valor normal.

Além disso, entende-se que os preços permitem cobrir os custos dentro de prazo razoável caso sejam superiores aos custos unitários médios ponderados relativos ao período da investigação.

\subsubsection{Origem das informações relativas a custos}

O Acordo também inova ao prever que os custos serão normalmente calculados com base nos registros do exportador ou do produtor submetido a inquérito, desde que respeitem os Princípios Fundamentais de Contabilidade e reflitam adequadamente os custos.

Releva observar, quanto a este item, que no caso dos semicondutores de memória de acesso randômico dinâmico (MARD) com capacidade de um megabit ou superior provenientes da Coréia $^{10}$, o Governo Coreano havia solicitado a uma consultoria independente que realizasse projeção de custos que, segundo o seu entender, respeitavam os princípios contábeis e refletiam adequadamente os custos.

10 WORLD TRADE ORGANISATION. Anti-dumping duty on dynamic random access memory semiconductors (DRAMS) of one megabyte or above originating from Korea. WT/DS99/R, § 6.66. Disponível em $<$ www.wto.org $>$ Acesso em 28 dez 2003. 
Os Estados Unidos desconsideraram tal projeção, tendo o painel que analisou o caso considerado que o procedimento era escorreito tendo em vista que tais projeções não poderiam ser consideradas registros mantidos pelo exportador ou produtor.

\subsubsection{Custos a serem considerados para a construção do preço}

O Acordo também buscou esclarecer o modo de determinação dos montantes correspondentes aos encargos de venda, às despesas administrativas e a outros encargos gerais, bem como aos lucros, para efeito de construção do preço normal. Os mesmos serão determinados com base em dados concretos relativos à produção e às vendas do produto similar no decurso de operações comerciais normais efetuadas pelo exportador ou produtor sujeito a inquérito.

Sempre que não for possível determinar estes montantes deste modo, serão determinados com base:

I) nos montantes efetivamente suportados e realizados pelo exportador ou produtor em questão no que respeita à produção e às vendas no mercado interno do país de origem da mesma categoria geral de produtos;

II) na média ponderada dos montantes efetivamente suportados e realizados por outros exportadores ou produtores objeto de inquérito no que respeita à produção e às vendas do produto similar no mercado interno do país de origem;

III) em qualquer outro método razoável, desde que o montante correspondente aos lucros determinado deste modo não exceda o lucro normalmente realizado por outros exportadores ou produtores sobre as vendas de produtos da mesma categoria geral no mercado interno do país de origem. 
O caso das roupas de cama indianas ${ }^{11}$ é rica fonte de subsídios para a interpretação dessa passagem do Acordo.

Uma das conclusões a que chegou o painel que examinou o caso é a de que inexiste qualquer hierarquia entre os métodos acima mencionados. Essa decisão, ainda que tenha parecido adequada ao caso, merece críticas, sobretudo ao se levar em conta o grande número de transações envolvendo preços de transferência. Isso porque o simples fato de se realizar uma investigação sobre dumping traz efeitos negativos sobre a economia de um país.

Por conta dessa realidade, talvez fosse aconselhável o estabelecimento de uma hierarquia entre os métodos, tal como pretendido pelo Governo Indiano, não pelo privilegiar de uma metodologia em detrimento da outra, mas sim pela utilização da menor margem de dumping obtida pela aplicação de qualquer dos métodos empregados ${ }^{12}$.

A legislação brasileira relativa a preços de transferência possui uma regra semelhante, relativa a dedutibilidade de despesas para efeitos fiscais em casos de operações entre pessoas associadas, na qual se determina a utilização, no caso de possibilidade de aplicação de mais de um método de determinação de preço, do maior valor de despesa encontrado ${ }^{13}$.

No mesmo caso, em relação à fonte dos dados, o painel entendeu que era possível, para a aplicação do método previsto no item II, a utilização dos dados de apenas um produtor, quando apenas os dados deste estiverem estavam disponíveis. O painel observou que inexistia no Acordo da Rodada Tóquio disposição similar ao item II mencionado, o que levava muitos países, sobretudo os Estados Unidos, a calcular o montante dos lucros e dos custos de venda, gerais e administrativos com base em padrões

11 WORLD TRADE ORGANISATION. European Communities - Anti-Dumping Duties on Imports of Cotton-Type Bed Linen from India: Report of the panel. WT/DS141/R. Disponível em <www.wto.org> Acesso em $28 \mathrm{dez} 2003$.

$12 \quad$ Lembrando-se aqui que muitos dos países que utilizam o Acordo realizam cálculos com base em preço construído exatamente para inflar a margem de dumping.

Lei no 9.430, de 27 de dezembro de 1996, art. 18, § 4\%. Disponível em <www.planalto.gov.br> Acesso em 8 jan 2004. 
estabelecidos sem qualquer referencia a informações relevantes colhidas no curso das investigações, e que o mencionado dispositivo busca, exatamente, evitar as arbitrariedades no cálculo dos custos ${ }^{14}$.

Outra questão abordada nesse caso foi a de que a Comunidade Européia utilizou no cálculo do montante previsto no item II apenas os montantes incorridos e realizados no curso normal dos negócios, e não o correspondente montante de todas as transações. O painel, nesse aspecto, concordou com tal procedimento, por entender que a consideração de vendas no curso normal dos negócios é um princípio que permeia todo o art. 2.2 do Acordo.

A Índia alegou que não deveria ser observado o método previsto no item II quando o montante de custos apurados não fosse razoável, o que se verificou no caso, pois a média de lucros apurada pela Comunidade Européia com base no método foi de $18,65 \%$, ao passo que a média de lucros no mercado doméstico, considerados todos os produtos da mesma categoria dos que foram investigados, é de 7,04\%, a média total de lucros é de 5,41\% e a média de lucros na negociação de roupas de cama provenientes do Egito e do Paquistão é de 6,1\% o que levaria a concluir, com base nessas informações, que a média dos lucros em negociações com a Comunidade Européia seria de 5,0\%. Assim, segundo o Governo Indiano, deveria ter sido observada a exigência de razoabilidade do montante prevista no item III do Art. 2.2.2 do Acordo.

O painel discordou de tal interpretação e concluiu que os valores encontrados com base nos incisos I e II do Art. 2.2.2 do Acordo são razoáveis pelo simples fato de seguirem a metodologia neles indicada, pelo que seria desnecessária a aplicação posterior de qualquer teste de razoabilidade.

\footnotetext{
14 É interessante mencionar que o painel reconheceu que havia outro produtor cujos dados poderiam ter sido utilizados, mas a Índia não questionou a não inclusão deste produtor na amostra, algo a que a Comunidade Européia estaria obrigada a realizar, tendo sido a outra companhia considerada pela Comunidade apenas como uma fonte de informações a ser utilizada caso aquela cujos dados foram requeridos não cooperassem. Desse modo, havia dados disponíveis de apenas um produtor, tendo o painel concluído que o fato de terem sido requeridos dados de outro produtor para servirem como reserva, ainda que não utilizados, era mera questão de fato que não necessitava de apreciação jurídica.
} 
O painel considerou, no caso, que não há necessidade de um teste de razoabilidade quando é utilizado o método previsto no item II do Art. 2.2.2, sendo o resultado obtido com a aplicação do método, conseqüentemente, razoável.

Por fim, o painel considerou que a prática de desconsideração de margens de dumping negativas apuradas para cada um dos produtos investigados pela Comunidade Européia, na determinação do montante total, era incompatível com o Acordo ${ }^{15}$.

\subsubsection{Associação entre exportador e importador}

Quanto à associação entre exportador e importador, o Acordo repete a cláusula da Rodada Kennedy a qual prevê o cálculo do preço de exportação com base no preço a que os produtos importados foram pela primeira vez revendidos a um comprador independente, ou no caso de os produtos não serem revendidos a um comprador independente ou não serem revendidos no estado em que foram importados, numa base razoável determinada pelas autoridades envolvidas.

Um caso paradigmático relativo a esse dispositivo é o dos produtos de aço laminado quente provenientes do Japão ${ }^{16}$, em que o Departamento de Comércio dos Estados Unidos (DCEU), constatando que as exportações japonesas eram realizadas para empresas associadas nos Estados Unidos realizou um teste, denominado arm's length, do seguinte modo: promoveu a exclusão das exportações efetuadas a empresas associadas quando o preço médio dessas vendas era inferior em $0,5 \%$ que o preço médio de vendas a empresas independentes, por considerá-las fora do curso normal dos negócios ${ }^{17}$.

Além disso, o DCEU promoveu, na determinação do preço no mercado doméstico japonês, a substituição dos preços considerados fora do curso normal do

\footnotetext{
15 No caso, a Comunidade Européia comparou as médias ponderadas do preço de exportação e do valor normal de cada um dos produtos de roupa de cama, a qual, em alguns casos, demonstrou um preço de exportação maior que o valor normal e, portanto, uma margem negativa de dumping. Quando do cálculo da média ponderada da margem de dumping global, a Comunidade Européia desconsiderou as margens de dumping negativas.

16 WORLD TRADE ORGANISATION. United States - Anti-dumping measures on certain hot rolled stell products from Japan: Report of the panel. WT/DS184/R Disponível em <www.wto.org> Acesso em 28 dez 2003.

17 Razão pela qual o teste é também denominado como teste dos $99,5 \%$ por cento.
} 
comércio determinados por aquele teste pelos das revendas dos produtos promovidas pelas empresas associadas dos Estados Unidos a empresas independentes naquele país.

O Japão considerou que tais práticas do DCEU eram inconsistentes com os artigos 2.1, 2.2 e 2.4 do Acordo, por considerar que o teste realizado pelos Estados Unidos não é razoável, que o Acordo não permite um teste nos moldes do praticado, que a diferença de $0,5 \%$ é muito pequena para que se possa afirmar que a venda de um determinado produto está fora do curso normal dos negócios. Além disso, segundo o Japão, o teste simplesmente rejeita preços mais baixos, mas considera os mais elevados sempre normais, o que provoca necessariamente a elevação da margem de dumping e, ademais, o teste não leva em conta o grau de variação dos preços, o provoca resultados distorcidos. Assim, segundo o Japão, um teste mais adequado seria, por exemplo, aquele que levasse em conta a freqüência e a magnitude da variação ${ }^{18}$.

Os Estados Unidos, por seu turno, consideraram que o teste dos 99,5 por cento é consentâneo com o art. 2.1 do Acordo, especialmente tendo em conta que o mencionado artigo não especifica como se deve determinar quando as vendas são realizadas no curso normal dos negócios, enfatizando ainda que, de um modo geral, as operações realizadas entre empresas associadas são suspeitas, fato esse reconhecido no art. 2.3 do Acordo, e que seu teste é mais transparente e concreto que os realizados por outros membros da OMC.

Além disso, consideraram a margem de $0,5 \%$ suficiente para afirmar que uma venda não foi realizada no curso normal dos negócios e que não há razão para se utilizar uma margem maior, a exemplo da de minimis utilizada no art. 5.8 do Acordo, qual seja, de dois por cento, tendo em conta, inclusive, que a margem de $0,5 \%$ já foi considerada adequada em outras controvérsias no âmbito da OMC, a exemplo do caso envolvendo

18 Os argumentos do Japão podem ser encontrados nos parágrafos 7.91 a 7.95 do relatório do painel. 
importação de semicondutores de memória de acesso randômico dinâmico (MARD) com capacidade de um megabit ou superior provenientes da Coréia ${ }^{19}$.

Os Estados Unidos argumentaram que o teste arm's length é preferível ao proposto pelo Japão porque tem seu foco na associação entre o produtor e o consumidor, ao passo que o método alternativo enfatiza o produto como objeto de análise. Afirmaram, ainda, que os preços anormalmente elevados seriam objeto de outra espécie de teste, que não o arm's length.

Quanto à substituição das vendas, os Estados Unidos argumentaram que nada no Acordo impedia a realização de tal procedimento, que não há regra esclarecendo como as vendas a pessoas associadas devem ser tratadas, que o art. 2.2 do Acordo apresenta uma clara preferência ao preço de venda no mercado doméstico ao invés das vendas a terceiro país ou do preço construído e, ao se ter em conta o argumento do Japão, pelo simples fato de as vendas terem sido realizadas a pessoas associadas, seria forçosa a utilização dos preços de vendas a terceiro país ou do preço construído com base no custo de produção.

Assim, em resumo, os Estados Unidos adotaram, no caso, o seguinte entendimento:

a) as vendas efetuadas a empresas associadas a um preço médio menor que $99,5 \%$ do preço médio de venda a empresas independentes são consideradas fora do curso normal dos negócios;

b) nesses casos, o preço da operação de venda às empresas associadas é, então, substituído pelo preço de revenda à primeira empresa independente, a fim de se determinar o preço parâmetro, ou preço normal da operação.

19 WORLD TRADE ORGANISATION. Anti-dumping duty on dynamic random access memory semiconductors (DRAMS) of one megabyte or above originating from Korea. WT/DS99/R Disponível em $<$ www.wto.org> Acesso em 28 dez 2003. 
O procedimento mencionado seria necessário para a eliminação de distorções nos preços, segundo o entendimento dos Estados Unidos ${ }^{20}$.

$\mathrm{Na}$ análise do caso, o painel observou inicialmente que o Acordo define que um produto é objeto de dumping quando introduzido no mercado de outro país a um preço inferior ao preço comparável do produto similar destinado ao consumo no país de exportação, no curso normal do comércio, sendo que o Acordo não define em que consiste esse curso normal dos negócios.

Ademais, os dois Estados concordaram que as vendas realizadas a empresas associadas podem não ser realizadas em condições normais de comércio, o que justificaria a utilização de algum método para definição dos preços do produto no mercado interno. A preocupação dos membros do painel acerca do teste arm's length não dizia respeito, diretamente, ao fato de as vendas serem ou não efetuadas em condições normais de comércio, mas sim a preços médios inferiores àqueles verificados em operações com pessoas não associadas.

O painel reconheceu que o teste arm's length não levava em conta preços anormalmente elevados e, portanto, fora das condições normais de comércio, como exige o Acordo e o fato de ser utilizado outro teste específico nesses casos não implicava, no entender do painel, afirmar que aquele teste é consentâneo com o Acordo.

Além disso, constatou que o referido teste nada mais faz que elevar o preço médio do produto e, conseqüentemente, da margem de dumping, uma vez que apenas desconsidera valores de venda inferiores a 99,5\% dos preços médios das vendas efetuadas a empresas não-associadas e, portanto, tal teste foi considerado não consentâneo com o Acordo.

Por fim, o painel considerou a substituição dos preços considerados fora do curso normal do comércio, conforme determinados pelo teste arm's lenght, pelos das

20 WORLD TRADE ORGANISATION. United States - Anti-dumping measures on certain hot rolled stell products from Japan: Report of the panel. WT/DS184/R Disponível em <www.wto.org> Acesso em 28 dez 2003. Os argumentos dos Estados Unidos podem ser encontrados nos parágrafos 7.96 a 7.101 . 
revendas dos produtos promovidas pelas empresas associadas dos Estados Unidos a empresas independentes naquele país como contrário ao Acordo Antidumping, por falta de expressa previsão no mesmo para a realização de tal procedimento.

Em relação ao texto do Acordo, um outro aspecto a considerar, ao se proceder à sua interpretação, é o fato de que o ele não define o que vêm a ser empresas associadas, deixando-o ao livre arbítrio das autoridades envolvidas. A mera discordância entre elas sobre a circusntância de serem, ou não, associadas as empresas pode servir de fundamento para a promoção de uma investigação antidumping.

Chega a ser impressionante o fato de que, para citar apenas dois exemplos, nem a legislação brasileira ${ }^{21}$, nem tampouco a existente na Comunidade Européia $^{22}$, não definem, em suas regulamentações internas, o que são empresas associadas. No caso do Brasil, poder-se-ia, quando muito, fazer uso, por analogia, do conceito previsto para os ajustes de preços de transferência estabelecido na legislação do imposto de renda ${ }^{23}$.

Dispõe o mencionado dispositivo que são associadas às pessoas domiciliadas no Brasil, quando domiciliadas no exterior: a matriz desta; sua filial ou sucursal; a pessoa física ou jurídica cuja participação societária no seu capital social a caracterize como sua controladora ou coligada; a pessoa jurídica que seja caracterizada como sua controlada ou coligada; a pessoa jurídica que estiver sob controle societário ou administrativo comum dos mesmos titulares da empresa domiciliada no Brasil ou quando pelo menos dez por cento do capital social de cada uma pertencer a uma mesma pessoa física ou jurídica; a pessoa física ou jurídica que, em conjunto com a pessoa jurídica domiciliada no Brasil, tiver participação societária no capital social de uma terceira pessoa jurídica, cuja soma as caracterizem como controladoras ou coligadas desta; a pessoa física ou jurídica que seja sua associada, na forma de consórcio ou condomínio, conforme definido na legislação brasileira, em qualquer empreendimento; a pessoa física que for parente ou afim até o terceiro grau, cônjuge ou companheiro de qualquer de seus diretores

21 Decreto no 1.602 , de 23 de agosto de 1995. Disponível em <www.planalto.gov.br> Acesso em 8 jan 2004.

22 Regulamento Comunitário no 384/96. Disponível em <www.europa.eu.int> Acesso em 8 jan 2004. Art. 23 da Lei no 9.430, de 1996. 
ou de seu sócio ou acionista controlador em participação direta ou indireta; a pessoa física ou jurídica que goze de exclusividade, como seu agente, distribuidor ou concessionário, para a compra e venda de bens, serviços ou direitos; a pessoa física ou jurídica em relação à qual a pessoa jurídica domiciliada no Brasil goze de exclusividade, como agente, distribuidora ou concessionária, para a compra e venda de bens, serviços ou direitos.

Apenas para efeito de comparação, menciona-se a seguir o conceito previsto na legislação específica antidumping dos Estados Unidos ${ }^{24}$ : os membros de uma família, incluindo irmãos e irmãs (colaterais ou germanos), esposo, antepassados, e descendentes; qualquer gerente ou diretor de uma organização e tal organização; sócios; empregador e empregado; qualquer pessoa diretamente ou indiretamente possuindo, controlando, ou detendo cinco por cento ou mais do capital com direito a voto de qualquer organização e tal organização; duas ou mais pessoas diretamente ou indiretamente controlando ou sendo controladas pela mesma pessoa, ou detendo controle comum de outra pessoa; o controlador de outra pessoa e esta, considerando-se, para os propósitos de consideração como pessoas associadas, que uma pessoa controla outra pessoa se está legalmente ou operacionalmente em posição de restringir ou dirigir as ações da outra pessoa.

Por fim, mencione-se que a associação de empresas tanto pode afetar o preço de exportação quanto o preço normal, circunstância essa que é praticamente ignorada pelo texto do Acordo. Assim, por exemplo, os Estados Unidos, no caso dos produtos de aço

24 Livre tradução do autor do disposto no Item 33 da Seção 771 do U.S. Antidumping Act de 1930, in verbis:

(33) Affiliated persons.--The following persons shall be considered to be "affiliated" or "affiliated persons":

(A) Members of a family, including brothers and sisters (whether by the whole or half blood), spouse, ancestors, and lineal descendants.

(B) Any officer or director of an organization and such organization.

(C) Partners.

(D) Employer and employee.

(E) Any person directly or indirectly owning, controlling, or holding with power to vote, 5 percent or more of the outstanding voting stock or shares of any organization and such organization.

(F) Two or more persons directly or indirectly controlling, controlled by, or under common control with, any person.

(G) Any person who controls any other person and such other person.

For purposes of this paragraph, a person shall be considered to control another person if the person is legally or operationally in a position to exercise restraint or direction over the other person.. 
laminado quente provenientes do Japão, substituiram os valores das vendas das empresas japonesas para efeito de determinação do preço normal.

É interessante observar que o Acordo utiliza critérios assemelhados aos dos preços independentes comparados (do inglês comparable uncontrolled price method) ${ }^{25}$ e do custo mais lucro (do inglês cost plus method) ${ }^{26}$ previstos pela OCDE para a determinação do preço normal, ao passo que utiliza um assemelhado ao preço de revenda menos lucro (do inglês resale price method) ${ }^{27}$ apenas para o preço de exportação.

\subsubsection{Comparação eqüitativa}

Seguindo a orientação do Art. VI do GATT, o Acordo prevê a realização de comparação eqüitativa entre o preço de exportação e o valor normal, a qual deve ser feita no mesmo estágio comercial, normalmente no ex fabrica, abrangendo vendas efetuadas em datas tão próximas quanto possível, tomando-se em conta as diferenças que possam afetar a comparabilidade dos preços, inovando o Acordo ao prever, em suas notas explicativas, que alguns dos fatores que afetam a comparabilidade podem se sobrepor, cabendo às autoridades assegurar a não duplicação de ajustamentos já efetuados.

Do mesmo modo, o Acordo prevê a necessidade de ajustamentos, nos casos de associação entre importador e exportador, para contemplar os custos incorridos entre a importação e a revenda, incluindo direitos e impostos, bem como os lucros auferidos, inovando o Acordo ao prever que, nesses casos, se a comparabilidade dos preços tiver sido afetada, as autoridades determinarão o valor normal num nível comercial equivalente ao do preço de exportação calculado ou farão os ajustamentos necessários, exigindo-se, ainda, que as autoridades indiquem às partes envolvidas as informações necessárias para assegurar uma comparação eqüitativa, não impondo às mesmas um ônus da prova desmesurado.

\footnotetext{
25 ORGANISATION FOR ECONOMIC CO-OPERATION AND DEVELOPMENT (OECD). Transfer Pricing Guidelines for Multinational Enterprises and Tax Administrations. Paris: OECD, 1995, p. II-2..

26 OECD. Op. cit., p. II-11.

27 OECD. Op. cit., p. II-5.
} 
O Acordo inova, ainda, ao aclarar o modo de conversão de moedas, a fim de assegurar a comparabilidade dos preços. Além disso, determina que a comparação será feita entre o valor normal médio ponderado e a média ponderada dos preços de todas as transações de exportação comparáveis ou, alternativamente, entre o valor normal e os preços de exportação, transação a transação.

Além dessas hipóteses prevê a possibilidade de comparação entre o valor normal determinado com base numa média ponderada e os preços de transações de exportação, consideradas individualmente, caso as autoridades constatem que existe uma configuração dos preços de exportação que difere de forma significativa consoante $o$ comprador, a região ou o período e caso seja dada uma explicação da razão pela qual essas diferenças não podem ser tomadas em devida consideração quando se recorre a uma comparação entre as médias ponderadas ou entre as transações.

\subsubsection{Produtos importados de terceiro país}

O Acordo segue o tratamento previsto desde aquele Acordo para o caso de produtos que não sejam diretamente importados de seu país de origem o qual, conforme já apontado, apresenta ambigüidades incompatíveis com a certeza e transparência necessárias às investigações dos processos envolvendo dumping ${ }^{28}$.

\subsection{Considerações finais}

Nota-se, pelo exposto, que a contribuição do GATT e da OMC no sentido de regulamentar de modo padronizado os casos de investigações antidumping têm sido bastante relevante, mormente quando se tem em conta a evolução, em termos numéricos, do nível de utilização do mencionado instrumento de regulação comercial, bem assim as tentativas de melhor regular os textos normativos sobre o tema.

Entretanto, é forçoso reconhecer que o comércio internacional evoluiu bastante desde 1946, sobretudo no que concerne à atuação das empresas multinacionais, o que não parece ser um aspecto adequadamente considerado pelo texto do Acordo. Conforme visto, cerca de sessenta por cento do comércio mundial é realizado por empresas

28 Artigo 2.5 do Acordo. 
multinacionais, o que demonstra a larga realização de operações entre empresas associadas, sendo que o mais recente acordo internacional em matéria de dumping, o da Rodada do Uruguai, sequer define quando se devem considerar associadas as empresas.

Além disso, o núcleo do mencionado acordo - exatamente as disposições relativas à comparação entre o preço normal e o preço de exportação - permite a imposição de deveres antidumping em situações nas quais, pela aplicação de outros métodos previstos no próprio texto, não estaria caracterizada a prática de dumping. Essa situação não é desejável tendo em vista os princípios que nortearam a criação do GATT e da própria OMC, entre eles a eliminação de barreiras injustificadas ao livre comércio e a busca de transparência nas relações comerciais internacionais.

Por fim, como já mencionado, na hipótese de associação de empresas, o Acordo permite a substituição do valor de exportação apenas pelo valor de revenda à primeira empresa independente no país importador. Essa é uma restrição incompreensível, ao se levar em conta que a maior parte dos produtos que vêm sendo objeto de investigações antidumping são insumos.

Outro organismo internacional com notável contribuição no estudo dos chamados preços de transferência, a OCDE, utiliza três critérios baseados nos produtos para a determinação dos preços: além do de revenda menos a margem de lucro, faz uso de preços independentes comparados (do inglês comparable uncontrolled price method) ${ }^{29}$ e de um preço construído a partir do custo acrescido da margem de lucro (do inglês cost plus method $)^{30}$, o que já é suficiente para demonstrar a aparente inadequação do Acordo nesse tocante.

A válvula de escape prevista no Acordo no caso de inexistência de revenda do produto no mesmo estado em que importado, qual seja, a determinação do preço

\footnotetext{
29 ORGANISATION FOR ECONOMIC CO-OPERATION AND DEVELOPMENT (OECD). Transfer Pricing Guidelines for Multinational Enterprises and Tax Administrations. Paris: OECD, 1995, p. II-2..

OECD. Op. cit., p. II-11.
} 
numa base razoável estabelecida pelas autoridades não é adequada, pois deixa uma margem de discricionariedade muito grande na mão do país que promove a investigação.

Outras considerações podem ser feitas, não-diretamente relacionadas a preços de transferência.

A primeira é a relativa à utilização do preço de exportação para um terceiro país: apesar de ter havido uma considerável melhora no Acordo do Uruguai ao se excluir a referência de que poderia ser utilizado o maior preço encontrado, desde que representativo, entende-se que seria aconselhável que o Acordo previsse, ao menos como fórmula exemplificativa, em que consiste a inexistência de vendas no curso normal das ações de comércio no mercado doméstico do país exportador ou quais as condições específicas de mercado que justificam a utilização de preços de venda a terceiros países.

Ainda em relação ao preço de exportação, o Acordo prevê a possibilidade de sua comparação com um preço normal construído a partir do custo de produção no país de origem, acrescido de um montante razoável para os encargos de venda, despesas administrativas e outros encargos gerais, bem como para os lucros, com base em dados concretos relativos à produção e às vendas do produto similar no decurso de operações comerciais normais efetuadas pelo exportador ou produtor sujeito a investigação.

Pois bem, na impossibilidade de sua determinação, o Acordo prevê três métodos a partir dos quais pode ser construído o preço, sendo o primeiro o relativo aos montantes efetivamente suportados e realizados pelo exportador ou produtor em questão no que respeita à produção e às vendas no mercado interno do país de origem da mesma categoria geral de produtos.

Nota-se, aqui, uma incoerência do Acordo: ele exige o cálculo dos custos e margem de lucro da mesma categoria geral de produtos, o que pode trazer complicações adicionais no cálculo, a exemplo do verificado no caso das roupas de cama indianas, tendo em vista que os valores para o produto - roupas de cama - diferiam daqueles previstos para a categoria - têxteis. 
Outro critério, como já visto, é a utilização da média ponderada dos montantes efetivamente suportados e realizados por outros exportadores ou produtores no que respeita à produção e às vendas do produto similar no mercado interno do país de origem. Esse critério pode causar grandes distorções no cálculo, ao se ter em conta o fato de a amostra utilizada não ser representativa do universo de produtores.

Lembra-se que, no caso indiano, a média foi calculada a partir de dados de apenas um produtor, havendo outros cujas informações estavam disponíveis. Discordase aqui, do decidido no painel, pois se havia mais de um produtor, a média deveria ter sido calculada com base nos dados de ambos e não apenas nos de um, servindo os dados do outro como uma espécie de fonte alternativa de dados ${ }^{31}$.

Apesar da aparente clareza desse método, é necessário ainda observar as divergências surgidas em sua interpretação no que concerne à desconsideração de margens de dumping negativas promovida pela Comunidade Européia, procedimento este repudiado pelo painel, bem assim pela interpretação dada por esta e confirmada pelo painel de que no cálculo da média somente devem ser levadas em conta operações em condições normais de mercado.

Quanto à utilização de qualquer outro método razoável, desde que o montante correspondente aos lucros determinado deste modo não exceda o lucro normalmente realizado por outros exportadores ou produtores sobre as vendas de produtos da mesma categoria geral no mercado interno do país de origem, novamente há que se criticar o Acordo: dois dos métodos são baseados na categoria geral de produtos (I e III), ao

31 A decisão parece ter sido nesse sentido pela inexistência de questionamento do Governo Indiano quanto a este aspecto. 
passo que um diz respeito apenas ao produto em si (II). Tal fato pode importar em determinação de prática de dumping pela simples divergência entre as metodologias de cálculo empregadas ${ }^{32}$.

\section{Referências bibliográficas}

1. FINGER, J. Michael. Safeguards: Making sense of GATT/WTO provisions allowing for import restrictions. In: HOEKMAN, Bernard. MATTOO, Aaditya. Development, trade, and the WTO: a handbook. Washington: World Bank, 2002.

2. JOHNSON, H. Thomas. KAPLAN, Robert S. Contabilidade gerencial: a restauração da relevância da contabilidade nas empresas. Tradução de Ivo Koryotowski. Rio de Janeiro: Campus, 1993.

3. ORGANISATION FOR ECONOMIC CO-OPERATION AND DEVELOPMENT (OECD). Transfer Pricing Guidelines for Multinational Enterprises and Tax Administrations. Paris: OECD, 1995.

4. SALA GALVAN, Gemma. Los Precios de transferencia internacionales: su tratamento tributario. Valencia: Tirant lo Blanch, 2003.

5. SMITH, Adam. A Riqueza das nações: Investigação sobre sua natureza e suas causas. Introdução de Edwin Cannan, apresentação de Winston Fritsch e tradução de Luiz João Baraúna. In Os Economistas. São Paulo: Nova Cultural, 1996. v. I.

6. THERON, Nicola. Anti-dumping procedures: lessons for developing countries with special emphasis on the South Africa Experience. Disponível em

\footnotetext{
32 Observa-se, por exemplo, que nos Estados Unidos o método de construção do valor normal é o mais utilizado nos casos de dumping, sendo que mais de dois terços dos casos do ano de 1987 envolveram os métodos de estabelecimento com base no custo de produção ou em outro valor construído, observando-se que foram impostos deveres antidumping em 89 por cento dos casos nos quais foi realizada a construção do valor normal, ao passo que o percentual no caso de utilização do preço do produto no mercado doméstico foi de 82 por cento e os de utilização de preços de exportação para terceiro país foram de apenas 32 por cento, o que parece indicar um viés que importa a determinação de prática de dumping na maior parte dos casos em que o valor construído é utilizado para determinação do valor normal. (THERON, Nicola. Anti-dumping procedures: lessons for developing countries with special emphasis on the South Africa Experience. Disponível em <http://www.sba.muohio.edu/abas /1998/anti-dumping.pdf > Acesso em 9 dez 2003, p. 6).
} 
$<$ http://www.sba.muohio.edu/abas /1998/anti-dumping.pdf > Acesso em $9 \mathrm{dez}$ 2003.

7. UNITED NATIONS. Transfer Pricing : History - State of the Art - Perspectives. Ad Hoc Group of Experts on International Cooperation in Tax Matters. Tenth meeting. Geneva, 10 - 14 September 2001. Disponível em www.un.org Acesso em 8 setembro 2003.

8. WORLD TRADE ORGANISATION. Acordo sobre a implementação do Artigo VI do Acordo Geral sobre Tarifas e Comércio 1994. Disponível em $<$ http://www.fd.uc.pt/ Acordo_Artigo_VI.htm> Acesso em 8 jan 2004.

9. - Agreement on Implementation of Article VI of the General Agreement on Tariffs and Trade. Geneva: 1963. Disponível em <www.wto.org> Acesso em 15 dez 2003.

10. - European Communities - Anti-Dumping Duties on Imports of Cotton-Type Bed Linen from India: Report of the panel. WT/DS141/R. Disponível em <www.wto.org> Acesso em $28 \mathrm{dez}$ 2003. Os argumentos da Índia podem encontram-se nos parágrafos 6.49 e 6.50 do relatório.

11. - United States - Anti-dumping measures on certain hot rolled stell products from Japan: Report of the panel. WT/DS184/R Disponível em $<$ www.wto.org> Acesso em 28 dez 2003. 